\title{
Automation of Ticket Booking Process for Performance (A Case Study of Aliero Community Theatre)
}

\author{
Sulaiman Umar S.Noma ${ }^{1}$, Badamasi Yusuf ${ }^{2}$ \\ Department of Computer Science, Kebbi State Polytechnic, Dakingari, Nigeria ${ }^{1}$ \\ Federal Inland Revenue Services (FIRS), Lagos Branch Office, Nigeria²
}

\begin{abstract}
Automation nowadays has already entered human lives, but in designing a valuable, reliable and usable automatic system, there's a need to conduct a critical investigation of the case studies in terms of functionality, information analysis, decision and action selection and action implementation. The complexity of automation design requires high logical process, related techniques and real execution. Every single part of the process should be clarified before starting. In this business competitive era, Information and Communication Technology is placed on a platform by many organizations as their key indicator for success. Online data handling and automation service have been a major tool to provide better customers service. This research consists of an outline of the analysis and design process of booking of tickets for performances at the Aliero Community Theatre (ACT) and evaluation of the product deliverables.
\end{abstract}

Keywords: Software Engineering, Unified Modelling Language (UML), ACT, Ticket Booking, Theatre

\section{INTRODUCTION}

The use of technology help in improving process or activities performance in terms of speed and accuracy. It help individual customer and agencies to access a required processes or activities from their homes or offices. The creation of technology and its application in order to control and monitor the production and delivery of various goods and services is refer to as automation (Jacky, 2019). It performs tasks that were previously performed by humans. Automation is being used in a number of areas such as manufacturing, transport, utilities, defense, facilities, operations and lately, information technology. In the manual system of tickets booking, customers are unable to booked ticket online at their comfort of time which may lead to queue up to booked a tickets ask for information (Adam, 2019). The automated ticketing system enable customers to book and make payment online, to check available convenient location and other information online. In the new proposed system, it aim to automate existing ticketing system to provide better customers services. In this work, the outline of conceptual view of the proposed system will be highlighted.

\section{FEASIBILITY STUDY}

2.1 Operational Feasibility: The proposed system is operationally feasible as it solves the inefficient manual ticketing service, very easy for the end users to operate, can be used effectively after it has been developed and allow the Aliero Community Theatre (ACT) staff to perform its operation efficiently. Therefore, the new system increases the performance as it satisfies customers' needs through timely and efficient service delivery.

2.2 Economical Feasibility: Economically, the proposed automated system will eliminates the time and money spent for process of manually booking ticket, reduces the consumption of paper and increases customers' satisfaction. The cost of this system is development cost which is related to purchasing of computers and developer salary, which is less than the benefit to be obtained after the system is deployed.

2.3 Technical Feasibility: The system needs to setup the facility of computers and the technology used for this new system are already existed and easily affordable. The technical skills to develop this system are also available.

\section{PROPOSED SYSTEM}

It is recommended to implement system solutions that attempts to rectify existing problems in the current ticketing system and propose an innovative way to enhance the ticketing services provided by the company. The proposed system enables customers to check the availability of tickets, booking ticket with prepaid card payment mode 


\section{International Journal of Advanced Research in Computer and Communication Engineering}

Vol. 8, Issue 12, December 2019

and viewing available information online. The system will handles ticketing activities efficiently, which can function as a catalyst in the competitive business environment regardless of the geographic barricades.

\subsection{DESIGN DECISION FOR THE PROPOSED SYSTEM}

The proposed system design pattern is in such a way that only valid users can have access to the system, it has strong authentication techniques, the new users can also select on create new account and fill on the necessary and compulsory information from new displayed window in the box provided. For new users registration is subject to verification and approval from admin, if the new users' registration is successful or not, the notification will be send to user email address provided.

The new customers' registration can be in to categories, the first category is for individual customer and the second category is for agencies or social clubs. For the agencies or social club, there's need to add their bank details, the system will have collaboration with their banks so that they can be charge directly from their account.

For the existing customers, they can login to the system online and view the available information which include available location of seats. Upon a booking process from an existing customers, available seat vacant will be display and the prices based on performance and location of seat. If customers successfully booked for a seat related to a particular performance and successfully made a payment, the receipt will be generated by the system and send to customers email address showing details of seat booked and payment. The discount will be shown in the receipt, for the agencies and social clubs that booked for less than 20 seats per performance, $5 \%$ discount will be removed out of the total price, if the seats booked are up to 20 or more, $10 \%$ discount will be deducted from the original total amount to be paid. For an individual customers, the discount will be $5 \%$. The booked details and discount will be shown clearly in the receipt generated by the system. The discount is for those that booked before the time of the performance.

In the new proposed system, there is a provision of a performance advert, users can view from the comfort of their offices or homes online.

\subsection{PROGRAMMING TOOL}

The development of the web pages can be made possible using the different technology of preference. PHP is chosen as web scripting language for the proposed system. PHP was chosen because it can independently ran on a server, and doesn't matter what type of Operating system you are using, it is likely to run in UNIX, a lot of people use it (widely used, and open source), Integrates with HTML, CSS, javascript, ajax, jquery very well, updated regularly, it has security and solid platform. The database design tool choose for excellent communication is WAMP server.

\subsection{FUNCTIONAL REQUIREMENTS}

Listed below are the functional requirements for the proposed system.

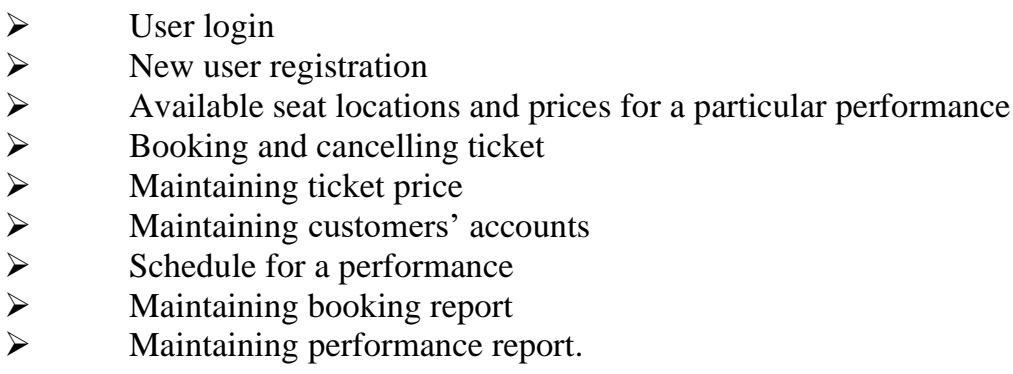

\subsection{NON FUNCTIONAL REQUIREMENTS}

Listed below are the nonfunctional requirements for the proposed ticketing system of Aliero Community Theatre (ACT).

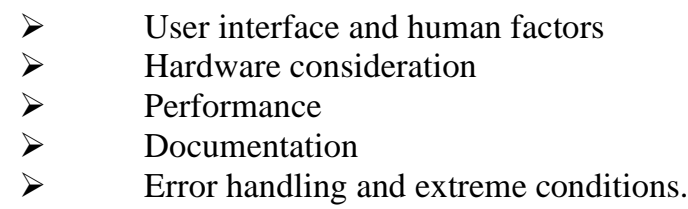

\subsection{SYSTEM TESTING}

System testing is the testing conducted to evaluate system performance with requirement specification, it help to evaluate system quality. Testing is a continuous process that should be performed at every stage of a software development process (Anderson, 2012). 
The system strategies chooses for the proposed system consists of both manual and automated testing.

Manual testing involves direct human interaction with the system under test, it include written test plan, scenarios to follow for the test and method of recording results.

Automated testing is the use of testing software to control the text execution and reporting.

\subsection{INFLUENCE OF THE PROPOSED SYSTEM}

It has major potential influences on the mobility of customers and services. It is also taken as an important enablers of changes in social and organizational practices. Technological trends will meet the demand for comfort, safety and speed through advances in ICT in terms of customers update on information, booking system and others activities of Aliero Community Theatre.

\section{DELIVERABLE}

For the proposed booking system of this research, the structure modeling process showing design pattern and flow of information is located in the UML design below.

\subsection{CONCEPTUAL AND DESIGN UML CLASS DIAGRAM}

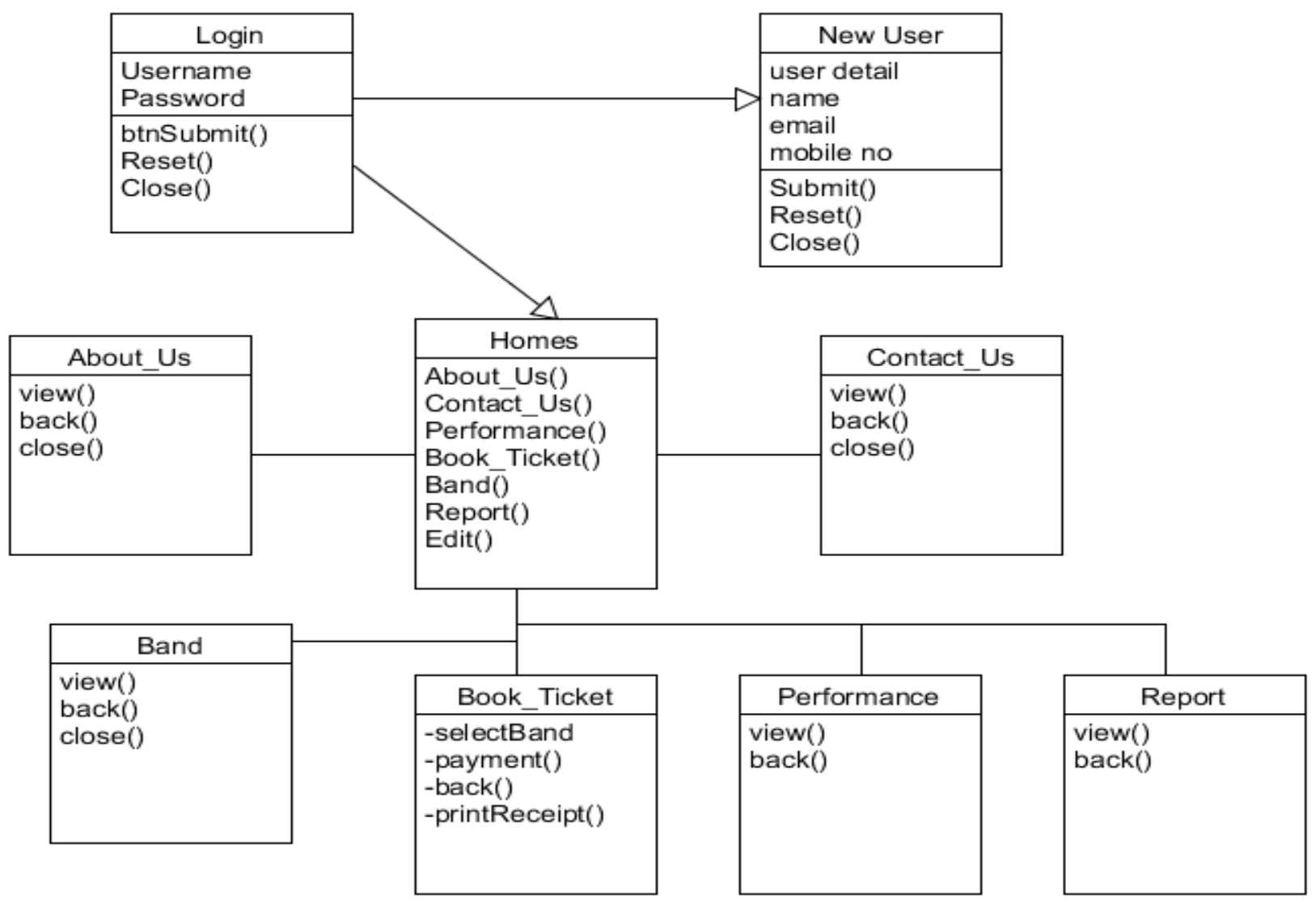

Figure 1: A Conceptual Class diagram for the proposed system 


\subsection{USE CASE DIAGRAM}

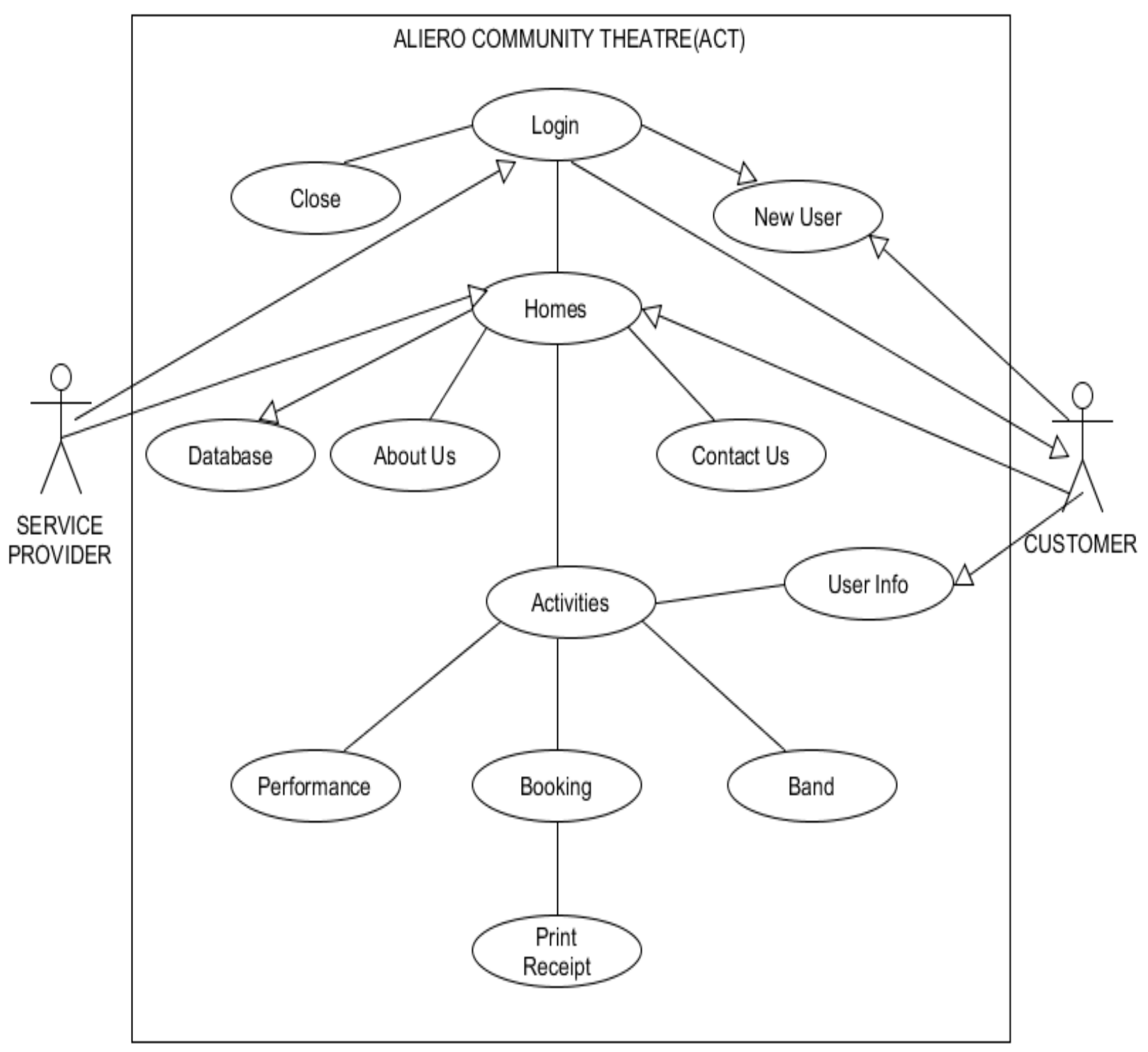

Figure 2: A Use Case diagram for the proposed system. 


\subsection{STATECHART DIAGRAM}

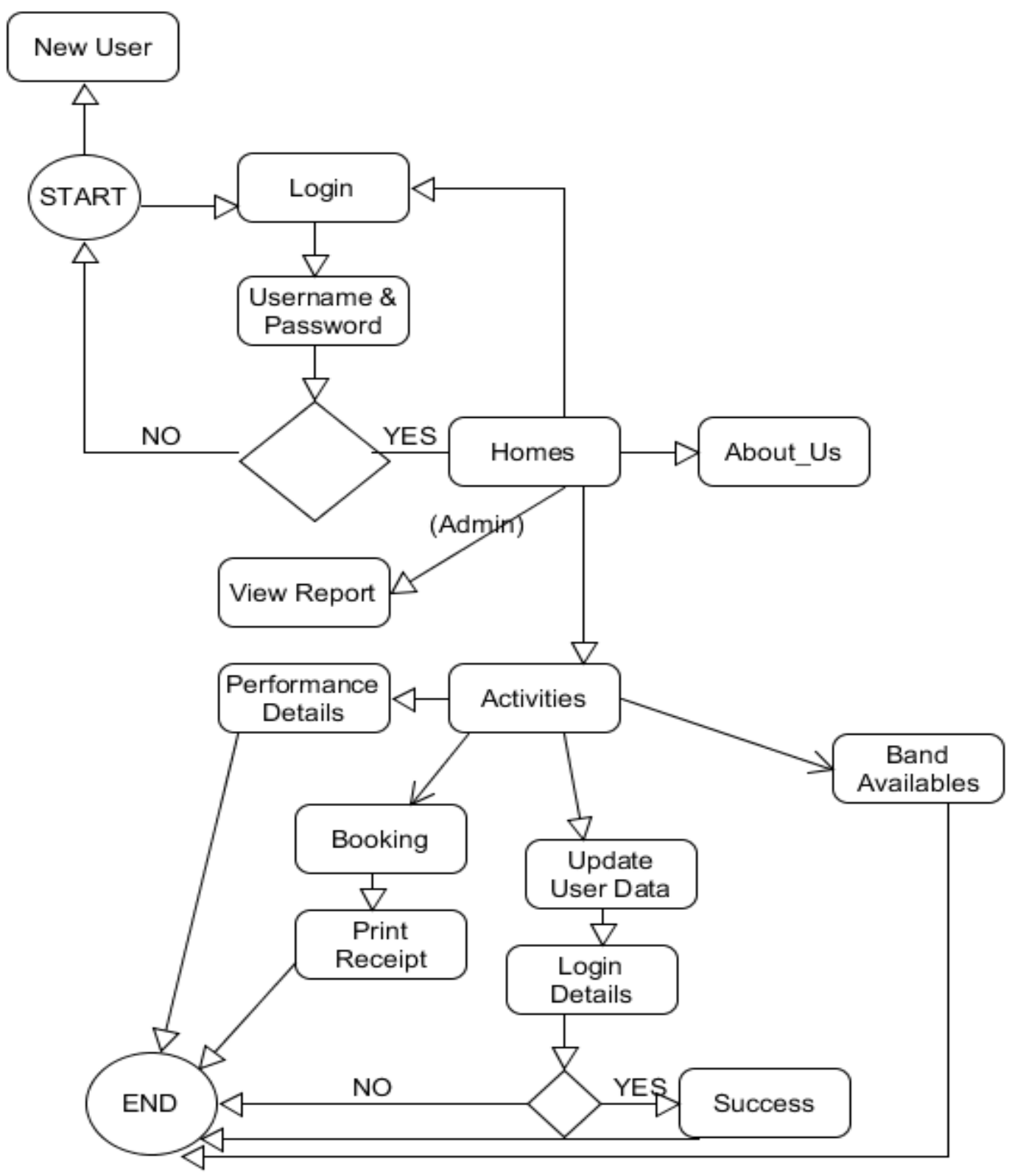

Figure 3: A StateChart diagram for the proposed system

\section{CONCLUSION}

Automated Ticketing System for Aliero Community Theatre (ACT) is useful for both the office management and customers. In depth study and implementation of the proposed system, there's need to have a clear view of the existing system in order to identify the relevant features of various components and methods needed for developing the new system. Developing online automated ticketing system creates convenience to customers to get ticket 24 hours per 7 days and the Aliero Community Theatre can perform its ticket service more efficiently. The Prepaid card payment system also easy and convenient for both management and customers. It also bring benefits including the ability to book ticket anywhere internet connection is available. In this report, the brief outline of the design process, programming tool and testing strategies of proposed system was stated and the conceptual design shown in the UML diagrams. 
Vol. 8, Issue 12, December 2019

\section{REFERENCES}

[1]. Adam, T., 2019. Automated Bus Ticket Reservation System for Ethiopian Bus Transport System. IOSR Journal of Computer Engineering (IOSR-JCE) , 21(3), p. 22.

[2]. Anderson, K. M., 2012. Introduction to Software Testing. CSCI 5828: Foundations of Software Engineering, 31 January, p. 11.

[3]. Jacky, J., 2019. Techopedia. [Online]

Available at: https://www.techopedia.com/definition/32099/automation

[Accessed 18 November 2019]. 